\title{
СОСТОЯНИЕ ЦИТОКИНОВОГО ЗВЕНА ИММУНИТЕТА У БОЛЬНЫХ С ПАРАРЕКТАЛЬНЫМИ СВИЩАМИ
}

\author{
(C) Заикин Е.Ю. ${ }^{1}$, Лазаренко В.А. ${ }^{1}$, Калуцкий П.В. ${ }^{2}$, Калуцкий А.П. ${ }^{l}$, Григорьев Н.Н. ${ }^{l}$ \\ ${ }^{1}$ Кафедра хирургических болезней ФПО, ${ }^{2}$ кафедра микробиологии, вирусологии, иммунологии \\ Курского государственного медицинского университета, Курск \\ E-mail: ohnza@mail.ru
}

\begin{abstract}
Исследован цитокиновый статус крови больных с параректальными свищами. Установлено, что развитие параректальных свищей сопровождается формированием выраженного дисбаланса про- и противовоспалительных цитокинов. Концентрация провоспалительных цитокинов (ФНО- $\alpha$, ИЛ-1 $\beta$, ИЛ-8) значительно (до 5,38 раза) превышали показатели здоровых лиц. В то же время увеличение концентрации противовоспалительного цитокина ИЛ-10 и рецепторного антагониста интерлейкина-1 было менее выраженным - 2,12-2,2 раза. При этом концентрация ИЛ-2 характеризовалась уменьшением в 1,8 раза по сравнению с показателями здоровых людей. Это может служить основой для неблагоприятного развития патологического процесса, поскольку дисбаланс в выработке цитокинов может нарушить существующие в локальной системе взаимосвязи, что в конечном итоге приводит к патологии регенерации.
\end{abstract}

Ключевые слова: параректальные свищи, цитокины, кровь.

\section{STATUS OF CYTOKINE IMMUNITY IN PATIENTS WITH ADRECTAL FISTULAS Zaikin E.Yu. ${ }^{l}$, Lazarenko V.A. ${ }^{l}$, Kalutsky P.V. ${ }^{2}$, Kalutsky A.P. ${ }^{l}$, Grigoryev N.N. ${ }^{l}$ \\ ${ }^{1}$ Department of Surgical Diseases of FPE, ${ }^{2}$ Department of Microbiology, Virology, Immunology of Kursk State Medical University, Kursk}

The cytokine blood status of patients with adrectal fistulas has been studied. It has been found that the development of an adrectal fistula is accompanied by the pronounced imbalance of pro- and anti-inflammatory cytokines. The concentration of pro-inflammatory cytokines (TNF- $\alpha$, IL-1 $\beta$, IL-8) significantly exceeded (as much as 5.38) that of healthy individuals. At the same time an increase in the concentration of anti-inflammatory cytokine IL-10 and receptor antagonist interleukin-1 was less pronounced (as less as 2.12 - 2.2). The concentration of IL-2 was as less as 1.8 compared with healthy controls. It may serve as the basis for the unfavorable development of the pathological process, since the imbalance in cytokine production can disturb the existing relationships in the local system, which ultimately leads to regeneration pathology.

Keywords: adrectal fistulas, cytokines, blood.

Хронический парапроктит, представляющий собой хронический воспалительный процесс в анальной крипте, межсфинктерном пространстве и параректальной клетчатке, сопровождающийся формированием свищевого хода, составляет 0,5-4\% от числа всех больных хирургического профиля и 15\% от числа больных, госпитализированных в специализированные отделения [5]. В структуре колопроктологических заболеваний параректальные свищи занимают одно из ведущих мест и встречаются в 20-40\% наблюдений [7]. Заболеваемость параректальными свищами составляет 2 случая на 10 тыс. населения в год [8]. Наиболее часто заболевание развивается в возрасте от 30 до 50 лет, что обусловливает социальную значимость данного заболевания. При этом мужчины страдают несколько чаще, чем женщины [8, 9, 10].

Установлено, что при заболеваниях, сопровождающихся нагноительным процессом, в том числе и парапроктите, наблюдаются выраженные сдвиги в состоянии клеточного и гуморального иммунитета, вплоть до развития вторичных иммунодефицитов [2, 3, 4], своевременное выявле- ние и коррекция которых являются одним из условий успешного лечения.

Целью настоящего исследования явилось изучение состояния цитокинового звена иммунитета крови больных параректальными свищами.

\section{МАТЕРИАЛЫ И МЕТОДЫ ИССЛЕДОВАНИЯ}

В исследовании на основе добровольного согласия приняли участие 30 больных в возрасте от 31 года до 60 лет, поступивших для лечения в колопроктологическое отделение ОГБУЗ «Белгородская областная клиническая больница святителя Иоасафа». У всех больных при поступлении производился забор венозной крови, в сыворотке которой методом твёрдофазного иммуноферментного анализа с помощью набора реагентов ВЕКТОР-БЕСТ (ООО «ВЕКТОР-БЕСТ», г. Новосибирск) оценивали уровни следующих цитокинов: ФНО- $\alpha$, интерлейкин-1 $\beta$ (ИЛ- $1 \beta)$, интерлейкин-2 (ИЛ-2), интерлейкин-8 (ИЛ-8), интерлейкин-10 (ИЛ-10), интерферон- $\gamma$ (ИНФ- $\gamma)$ и рецепторный антагонист интерлейкина-1 (РАИЛ-1). 
В качестве контроля использовали результаты исследований показателей у 20 здоровых добровольцев

Обработка результатов исследования проводилась методами непараметрической статистики. Существенность различий средних величин оценивали по критерию Вилкоксона-МаннаУитни [6]. При оценке достоверности различий сравниваемых данных за уровень значимости принимали $\mathrm{p}<0,05$.

\section{РЕЗУЛЬТАТЫ ИССЛЕДОВАНИЯ И ИХ ОБСУЖДЕНИЕ}

Анализируя уровень провоспалительных цитокинов, необходимо отметить их различную реакцию на развитие патологического процесса (рис. 1). Наиболее выраженной она была со стороны ИЛ-8, а наименее выраженной - со стороны ФНО- $\alpha$. Поскольку мишенью действия этих цитокинов являются гранулоциты, макрофаги, Т- и В-лимфоциты, то такое выраженное повышение их концентрации ведет к активации клеточного звена иммунитета. При этом в ответ на значительное (в 5,38 раза) увеличение одного из ключевых провоспалительных цитокинов ИЛ- $1 \beta$, который инициирует и регулирует воспалительные, иммунные процессы, активирует нейтрофилы, Т- и В-лимфоциты, стимулирует синтез белков острой фазы, цитокинов, молекул адгезии, простагландинов, запускает реакции воспалительно-регуляторного каскада, стимулирует синтез коллагена, имеет место менее выраженная стимуляция продукции его антагониста РАИЛ-1 (в 2,12 раза). Это свидетельствует о недостаточном регулировании эффектов ИЛ- $1 \beta$ в клеточном микроокружении.
Что касается такого противоспалительного цитокина, как ИЛ-10, то хотя и отмечена стимуляция его продукции в 2,2 раза, тем не менее она была неадекватной продукции провоспалительных цитокинов. В какой-то степени это может быть следствием повышения в 5,58 раза концентрации ИНФ- $\gamma$, который наряду с другими цитокинами ингибирует выработку ИЛ-10 в активированных моноцитах. С учетом механизма действия ИЛ-10 можно предположить повышение активности Т-хелперов II типа у данных больных.

Плейотропный цитокин ИЛ-2 запускает иммунный ответ, способствует увеличению экспрессии МНC I класса, что улучшает распознаваемость чужеродных антигенов, стимулирует пролиферацию и активацию натуральных киллеров и цитотоксических лимфоцитов, обладает выраженной способностью индуцировать активность практически всех клонов цитотоксических клеток, а также активирует моноциты и макрофаги. С другой стороны, он играет ключевую роль в апоптозе $\mathrm{CD}^{+} \mathrm{T}$-лимфоцитов в ответ на антигенную рестимуляцию. Однако, в отличие от других исследованных цитокинов, его концентрация не только не увеличилась по сравнению со здоровыми людьми, но и снизилась в 1,8 раза.

Таким образом, проведенное исследование выявило различную реакцию со стороны цитокинового звена иммунитета у больных с параректальными свищами. При этом неодинаковый характер реакции на развитие патологического процесса регистрировался не только среди цитокинов различных групп, но и внутри группы провоспалительных цитокинов. Последнее может быть связано с особенностями биологических характеристик исследованных представителей данной группы цитокинов.

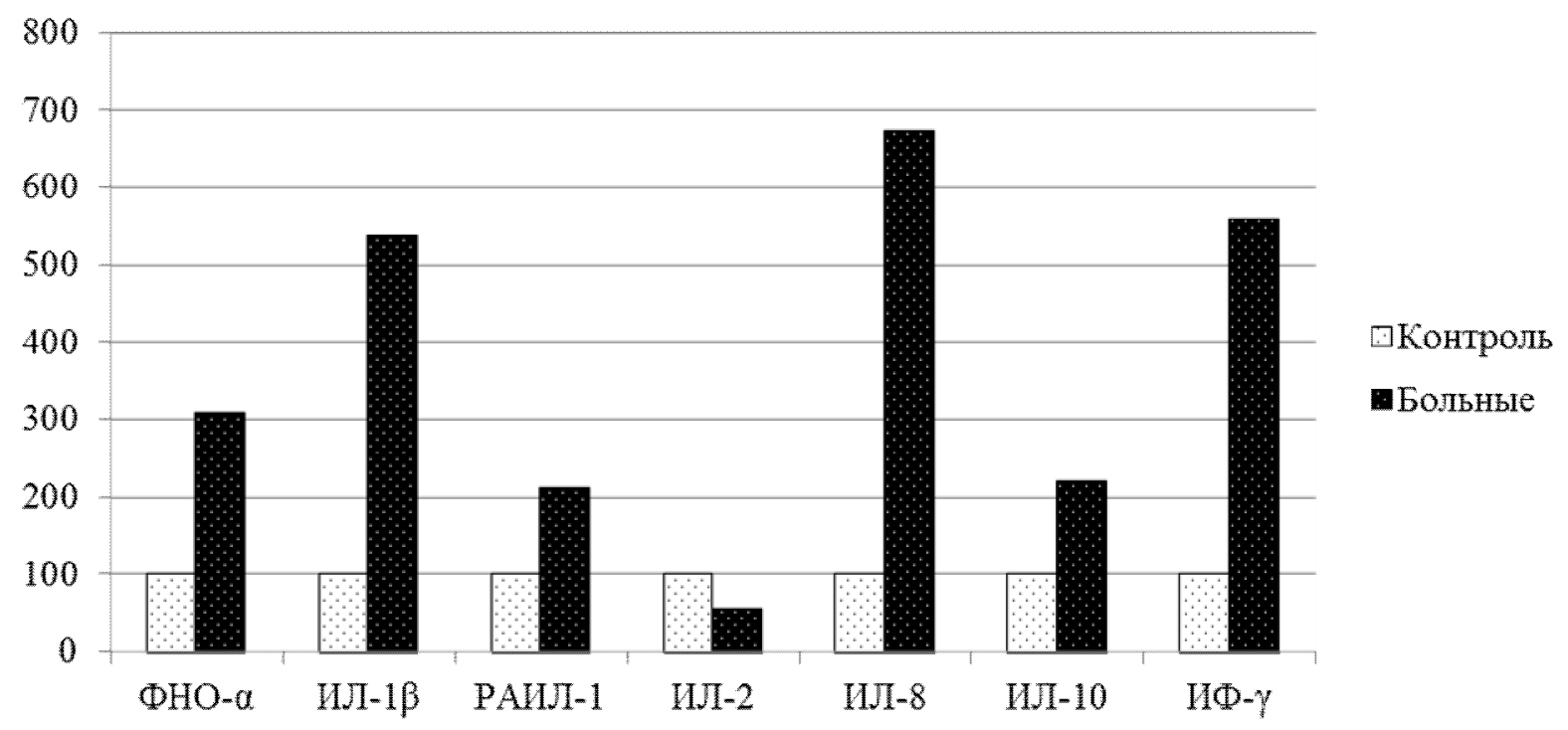

Рис. 1. Уровень цитокинов в сыворотке крови больных с параректальными свищами (показатели группы контроля приняты за 100\%). 
Неадекватная ответная реакция противовоспалительных цитокинов может служить основой для неблагоприятного развития патологического процесса, поскольку дисбаланс в выработке цитокинов может нарушить существующие в локальной системе взаимосвязи, что в конечном итоге приводит к патологии регенерации [1].

\section{ЛИТЕРАТУРА}

1. Вялов С.Л., Пшениснов К.П., Куиндоз Д. Современные представления о регуляции процесса заживления ран: Обзор литературы // Анналы пластической, реконструктивной и эстетической хирургии. 1999. - № 1. - С. 49-56.

2. Завада Н.В., Гаин Ю.М., Алексеев С.А. Хирургический сепсис: учеб. пособие для мед. вузов. Минск : Новое знание, 2003. -236 с.

3. Кузин М.И., Шкроб О.С., Кузин Н.М., Ветшев П.С., Кулакова А.М., Чистов Л.В., Чистова М.А., Успенский Л.В., Кайдам А.Н., Артюхина Е.Г., Крылов Н.Н. Хирургические болезни: Учебник / Под ред. М.И. Кузина. - 3-е изд., перераб. и доп. М. : Медицина, 2002. - 784 с.
4. Кузник Б.И., Хавинсон В.Х., Морозов В.Г. Пептидные биорегуляторы. - М. : Вузовская книга, 2004. - 402 c.

5. Кузьминов А.М., Минбаев Ш.Т., Королик В.Ю., Орлова Л.П., Фоменко О.Ю., Полякова Н.А., Сафоян А.А., Хермез С.М. Лечение экстрасфинктерных свищей прямой кишки с применением биопластического материала. - Российский журнал гастроэнтерологии, гепатологии, колопроктологии. - 2012. - № 5. - С. 76-82

6. Реброва О.Ю. Статистический анализ медицинских данных. Применение пакета программ Statistica. - М. : Медиасфера, 2002. - 312 c.

7. Федоров В.Д., Дульиев Ю.В. Проктология. - М. : Медицина, 1984. - 384 с.

8. Zanotti C., Martinez-Puente C., Pascual I., Pascual M., Herreros D., García-Olmo D. An assessment of the incidence of fistula-in-ano in four countries of the European Union. // Int J Colorectal Dis. - 2007. Vol. 22, N 12. - P. 1459-1462.

9. Ommer A., Herold A., Berg E., Fürst A., Sailer M., Schiedeck T. Cryptoglandular Anal Fistulas // Dtsch. Arztebl. Int. - 2011. - Vol. 108, N 42. - P. 707-713.

10. Sainio $P$. Fistula-in-ano in a defined population. Incidence and epidemiological aspects // Ann. Chir. Gynaecol. - 1984. - Vol. 73, N 4. - P. 219-224. 